\title{
MOBILE PHONE USE AND RISK FOR INTRACRANIAL TUMORS AND SALIVARY GLAND TUMORS - A META-ANALYSIS
}

ALICJA BORTKIEWICZ1 ${ }^{1}$, ELŻBIETA GADZICKA ${ }^{1}$, and WIESŁAW SZYMCZAK²

${ }^{1}$ Nofer Institute of Occupational Medicine, Łódź, Poland

Department of Work Physiology and Ergonomics

${ }^{2}$ University of Lodz, Lódź, Poland

Faculty of Educational Sciences, Institute of Psychology, Chair of Psychological Research Methodology and Statistics

\begin{abstract}
Results of epidemiological studies on the association between use of mobile phone and brain cancer are ambiguous, as well as the results of 5 meta-analysis studies published to date. Since the last meta-analysis (2009), new case-control studies have been published, which theoretically could affect the conclusions on this relationship. Therefore, we decided to perform a new meta-analysis. We conducted a systematic review of multiple electronic data bases for relevant publications. The inclusion criteria were: original papers, case-control studies, published till the end of March 2014, measures of association (point estimates as odds ratio and confidence interval of the effect measured), data on individual exposure. Twenty four studies (26 846 cases, 50013 controls) were included into the meta-analysis. A significantly higher risk of an intracranial tumor (all types) was noted for the period of mobile phone use over 10 years (odds ratio (OR) $=1.324,95 \%$ confidence interval (CI): 1.028-1.704), and for the ipsilateral location ( $\mathrm{OR}=1.249,95 \% \mathrm{CI}$ : $1.022-1.526)$. The results support the hypothesis that long-term use of mobile phone increases risk of intracranial tumors, especially in the case of ipsilateral exposure. Further studies are needed to confirm this relationship. Int J Occup Med Environ Health 2017;30(1):27-43
\end{abstract}

Key words:

Electromagnetic fields, Brain tumors, Acoustic neuroma, Salivary gland tumors, Cellular phone, Case-control studies

\section{INTRODUCTION}

Since mobile phones are becoming more and more popular, there has been a growing concern about possible detrimental effects of electromagnetic fields generated by them, such as impaired brain function and development of intracranial tumors in particular.

A lot of studies have been performed to explain the relationship between intracranial cancer and mobile phone use.
Research on health effects of mobile phone electromagnetic field (EMF) has been performed under various projects, such as: International EMF Project - World Health Organization (WHO), Fifth, Sixth and Seventh Framework Programmes of the European Community for Research, Technological Development and Demonstration Activities - European Union (EU), Wireless Technology Research (WTR) and Cooperative Research and

Funding: this study was supported by the National Committee for Scientific Research (KBN) in Poland (project number IMP 10.3). Title of the project: "The association between EMF emitted by mobile phones and the occurrence of intracranial tumors-meta-analysis.” Project manager: Prof. Wiesław Szymczak.

Received: September 17, 2015. Accepted: June 14, 2016.

Corresponding author: A. Bortkiewicz, Nofer Institute of Occupational Medicine, Department of Work Physiology and Ergonomics, św. Teresy 8, 91-348 Łódź, Poland (e-mail: alab@imp.lodz.pl). 
Development (CRADA) - the United States of America (USA). Results of these studies are ambiguous.

Recently, results of a multicenter case-control project INTERPHONE have been published, which was participated by partners from 13 countries (Australia, Denmark, Finland, France, Israel, Japan, Canada, Germany, Norway, New Zealand, Sweden, United Kingdom (UK) and Italy). The analysis of the results of a study conducted under the INTERPHONE project did not show increased risk of glioma or meningioma in cellular phone users [1]. However, the authors point to the necessity to perform further studies in long term users.

Some authors report that prolonged use of mobile phones increases the risk of intracranial tumors, especially glioma and acoustic neuroma, i.e., vestibular schwannoma. Hardell et al. (1999) [2] detected among mobile phone users a significant increase in the risk of brain tumor (odds ratio $(\mathrm{OR})=1.3,95 \%$ confidence inter$\operatorname{val}(\mathrm{CI})$ : 1.04-1.6), with ipsilateral tumor location both for analogue $(\mathrm{OR}=1.7,95 \% \mathrm{CI}: 1.1-2.7)$ and digital phones $(\mathrm{OR}=1.5,95 \% \mathrm{CI}: 1.1-2.3)$, a significant increase in the risk of acoustic neuroma compared to people not using mobile phones ( $\mathrm{OR}=4.4,95 \% \mathrm{CI}: 2.1-9.2)$ and a significant increase in the risk of vestibular schwannoma for analogue phones ( $\mathrm{OR}=3.45,95 \% \mathrm{CI}$ : 1.77-6.76).

In Hepworth et al. (2006) [3] case-control study a significantly increased risk of glioma in the ipsilateral location $(\mathrm{OR}=1.24,95 \% \mathrm{CI}: 1.02-1.52)$ was found in people using mobile phones on a regular basis. An increased risk of glioma was found also by Schüz et al. (2006) [4] in patients using mobile phones for periods over 10 years (OR $=2.2,95 \%$ CI: 0.94-5.11). Auvinen et al. (2002) [5] in a case control study demonstrated a significantly higher risk of glioma in analogue mobile phone users (OR $=2.1,95 \%$ CI: 1.3-3.4). Lakhola et al. (2007) [6] also report a significantly higher risk of ipsilateral glioma in their study conducted in Denmark, UK, Norway, Finland, and Sweden (OR $=1.4,95 \%$ CI: $1.01-1.9)$.
Inskip et al. (2001) [7], on the other hand, failed to note a significantly higher risk of brain tumors among mobile phone users.

None of the studies confirmed a relationship between mobile phone use and meningioma. The recently published results of case-control studies performed under the INTERPHONE project by Lahkola et al. (2008) [8] in 5 North European countries among people using mobile phones on a regular basis (1209 meningioma cases and 3299 controls) did not show a relationship between mobile phone use and the risk of meningioma $(\mathrm{OR}=0.76,95 \%$ CI: 0.65-0.89). In those studies, regular mobile phone use was defined as use at least once a week for at least 6 months.

Lönn et al. (2004) [9] analyzed the risk of acoustic neuroma in relation to the time of mobile phone use and location. The authors noted a significant increase in the risk of acoustic neuroma in the ipsilateral location in subjects who were using mobile phones for longer than 10 years $(\mathrm{OR}=3.1,95 \%$ CI: 1.2-8.4). No such relationship was recorded by these authors for the contralateral location.

As for parotid gland tumors (PGT), 2 studies (Sweden and other Nordic Countries) found no increased risk of PGT [4,5,10,11], while Sadetzki et al. (2008) [12] recorded a significantly higher risk in regular, heavy users for ipsilateral use. For people with a higher cumulative number of calls, the risk was 1.58 (95\% CI: 1.112.24), and for people with the longest call time, the risk was 1.49 (95\% CI: 1.05-2.13).

However, epidemiological studies performed heretofore have failed to provide a conclusive answer to the question about a cause-effect relationship between the incidence of intracranial tumors and mobile phone use, but their interpretation has been encumbered with some limitations.

\section{The risk of bias in particular case-control studies}

The cited studies may have been vitiated by an error due to 4 main reasons: 
1. The most serious doubts arise from exposure assessment, which was usually insufficient.

In most of the cohort studies it was limited to the statement that the person was a mobile phone subscriber (information from the operators). Unfortunately, data from mobile phone system subscriber lists does not provide information on true mobile phone use, because having a mobile phone is not equivalent to using it. In other studies, it was limited to the statement - "telephone use likely or certain" [4,13].

In case-control studies, exposure assessment was obtained by interviewing patients, often in grave condition shortly after the surgery. The authors reported that the patients often refused to respond, or did not remember the details of mobile phone use, and some other cases were fatal before the patient could be interviewed. Therefore, information was obtained only from a small number of the subjects. For example, in the studies by Inskip et al. (2001) [7], only $12 \%$ of the subjects from the exposed group and $3 \%$ of the controls were interviewed on mobile phone use. The small number of the interviewed patients reduces the reliability of the results.

In some studies, regular mobile phone use was defined as use at least once a week for at least 6 months [14]. The resultant exposure assessment is far from being precise, because it does not say what proportion of subjects in the regular user group used mobile phone occasionally (once per week) or how numerous was the group using it on a truly regular basis (i.e., several times a day).

2. The reasons quoted above cause that cases may be incorrectly assigned to individual groups differing in the intensity of mobile phone use.

Another problem noted by Hardell et al. (2004, 2006) $[15,16]$ and by Hansson Mild et al. (2005) [17] is that in some studies, people using cordless phones were classified as mobile phone non-users, while some other authors classified them as mobile phone users.
The analysis of the association between tumor development and the use of analogue or digital mobile phones is encumbered with an error, because most of the longtime users started with analogue, then shifted to digital mobile phones, and information is missing on when, if ever, the shift took place. Thus, the increased risk of cancer from analogue phone use indicated by some authors could be attributable to a long period of mobile phone use rather than to mobile phone type.

3. Long latency of intracranial tumors.

Some studies refer to people using mobile phone for 2-5 years. In some studies, regular mobile phone use was defined as use for at least 6 months [18]. This is too short to produce any evident symptoms of cancer. Thus, the negative outcome of the studies (i.e., no relation between mobile phone use and tumor) does not prove that mobile phones exert no effect on tumor development.

4. Another major limitation is that intracranial tumors are extremely rare in the general population, and it was difficult to obtain a sufficiently large number of cases. In such instance, meta-analysis makes it possible to use the published results of studies performed in various countries and include a larger number of cases.

The discrepancies among the different studies were discussed in details by Croft et al. (2008) [19], Levis et al. (2011) [20], Repacholi et al. (2012) [21] and lately Szmigielski (2013) [22]. Five meta-analysis studies have been published to date by Lahkola et al. (2006) [18], Hardell et al. (2008) [23], Kan et al. (2008) [24], Khurana et al. (2009) [25], Myung et al. (2009) [26], but their results are also ambiguous. This may result, among other things, from applying different criteria for the selection of studies to be included in the analysis and using different methods of the statistical analysis. Additionally, since the last (2009) meta-analysis, new case-control studies have been published, which theoretically could affect the conclusions on the relationship between the use of mobile phones and intracranial tumors. Therefore, we decided to perform another meta-analysis. 


\section{MATERIAL AND METHODS}

The study protocol was as follows: the relevant literature was reviewed by analyzing the databases: PubMed, BENER Digest Update/EMF Database/EMF Health Report, MEDLINE, and summary reports (International Commission on Non-Ionizing Radiation Protection (ICNIRP), WHO Statement, Royal Society of Canada Expert Panel Report, and the report of the EU Scientific Committee on Toxicity, Ecotoxicity and the Environment).

The PubMed was main source of papers, while the other bases were the complementary source of information. The search was conducted using key words: glioma, meningioma, salivary gland cancer, acoustic neuroma, i.e., vestibular schwannoma, facial neuroma and uveal melanoma, brain tumors, intracranial tumors, mobile phone, cellular phone, electromagnetic fields, radiofrequency electromagnetic fields. As a result of searching PubMed using the key words indicated above, there were 470 papers found. The analysis was limited to the use of cell phones, both analogue and digital (with the exclusion of cordless phones). As many as 21 casecontrol studies on intracranial tumors and mobile phone use were included, which met following inclusion criteria (Table 1):

- papers in English,

- original, case-control peer-reviewed studies published till the end of March 2014,

- measures of association (odds ratio and confidence interval of the effect measured),

- data on individual exposure.

However, some of the data was not fully useful, because only the relative risk was specified without the relevant information on the number of cases.

The studies analyzed the frequency of various tumors, both benign and malignant, including glioma, meningioma, salivary gland cancer, acoustic neuroma, i.e., vestibular schwannoma, facial neuroma and uveal melanoma.
The relationship was analyzed between mobile phone use and:

- total number of intracranial tumors,

- tumors by types.

All case-control studies specifying the duration of mobile phone use were considered, even though it was too short to suspect a cause-effect relationship between EMF exposure and tumor. The studies including subjects using mobile phones for longer than 10 years were additionally analyzed separately. Such period of latency causes that the suspected relationship between cellular phone use and the development of tumor becomes more likely.

In this instance, studies specifying both the time of regular mobile phone use over 10 years ( 9 studies), and the time since the first regular use of 10 years or more (14 studies) were considered, in spite of the fact that the latter parameter is not precisely defined. They may refer to people who started regularly using mobile phones over 10 years ago, but did not continue using it regularly during the whole 10-year period. Therefore, the studies that contained those 2 types of definition of telephone use time were not combined into one group.

The following relationships were analyzed:

1. All intracranial tumors and all mobile phone types.

2. All brain tumors and analogue phones.

3. Glioma and all mobile phone types.

4. Meningioma and all mobile phone types.

5. Acoustic neuroma and all mobile phone types.

6. All intracranial tumors and all phone types; time of mobile phone use not shorter than 10 years.

7. All intracranial tumors and all phone types; time from the first regular use of mobile phone of 10 years or more.

8. All intracranial tumors and all phone types; ipsilateral exposure. The contralateral studies were disregarded, as none of them revealed an association between tumor in that location and the use of mobile phone. 


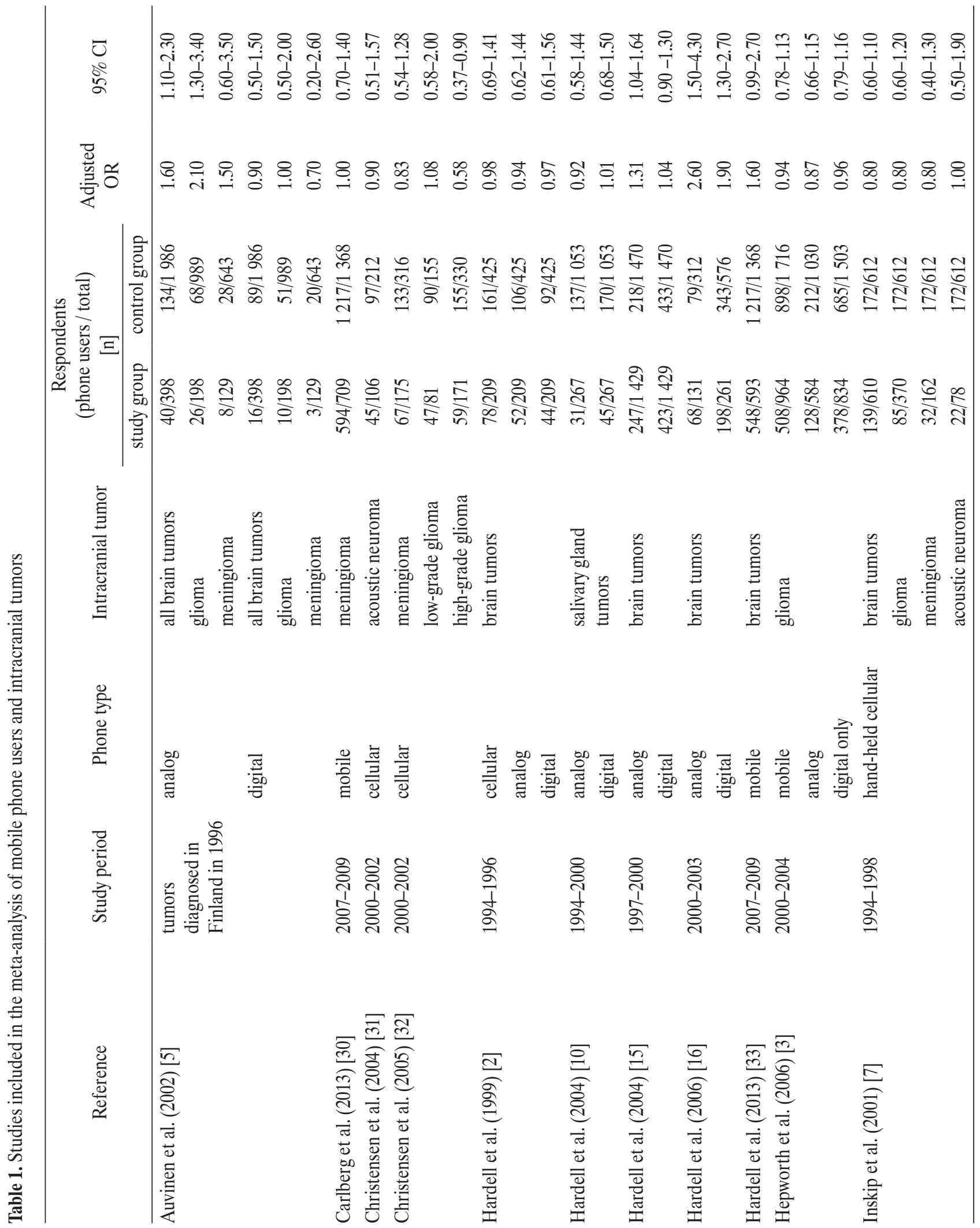




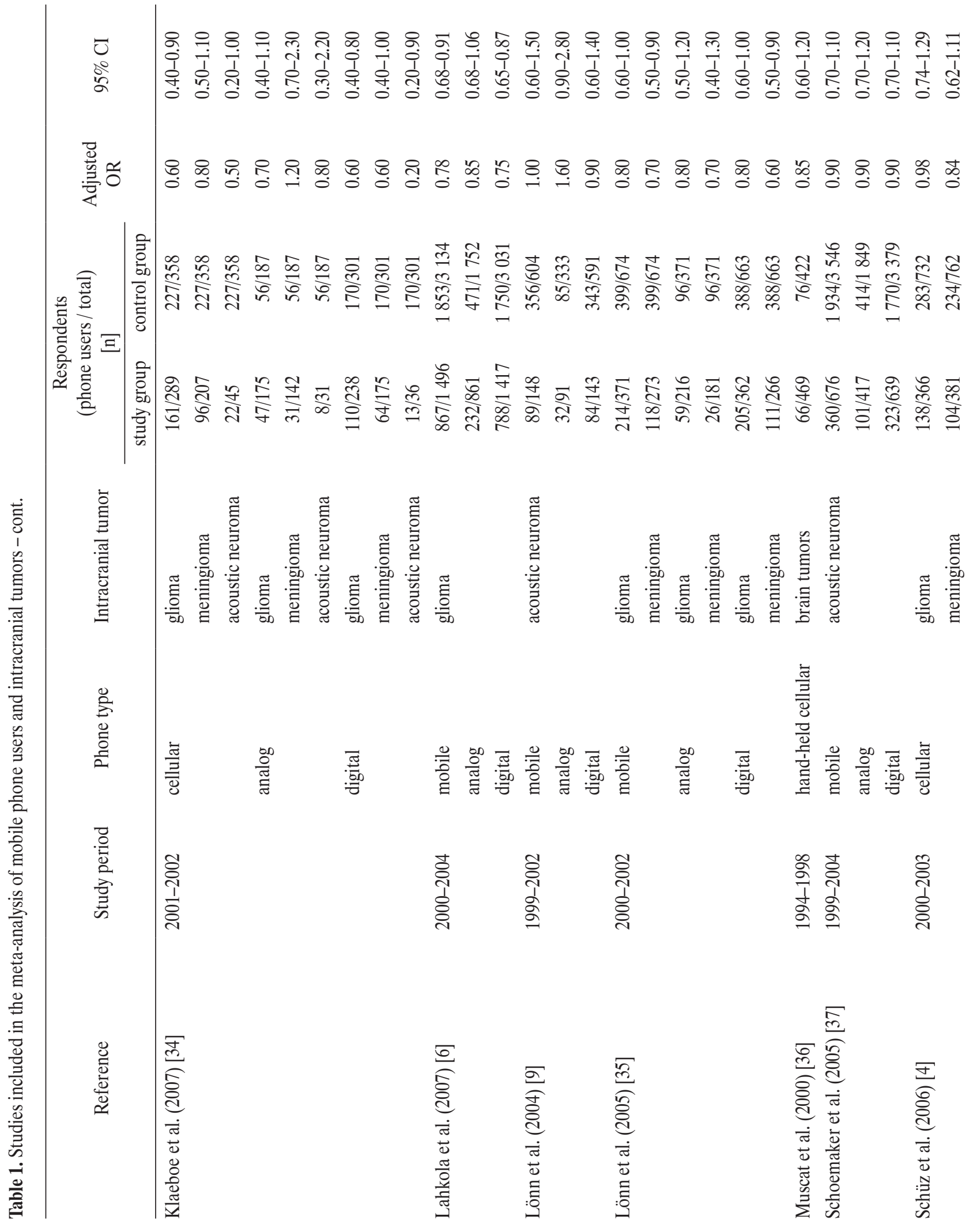




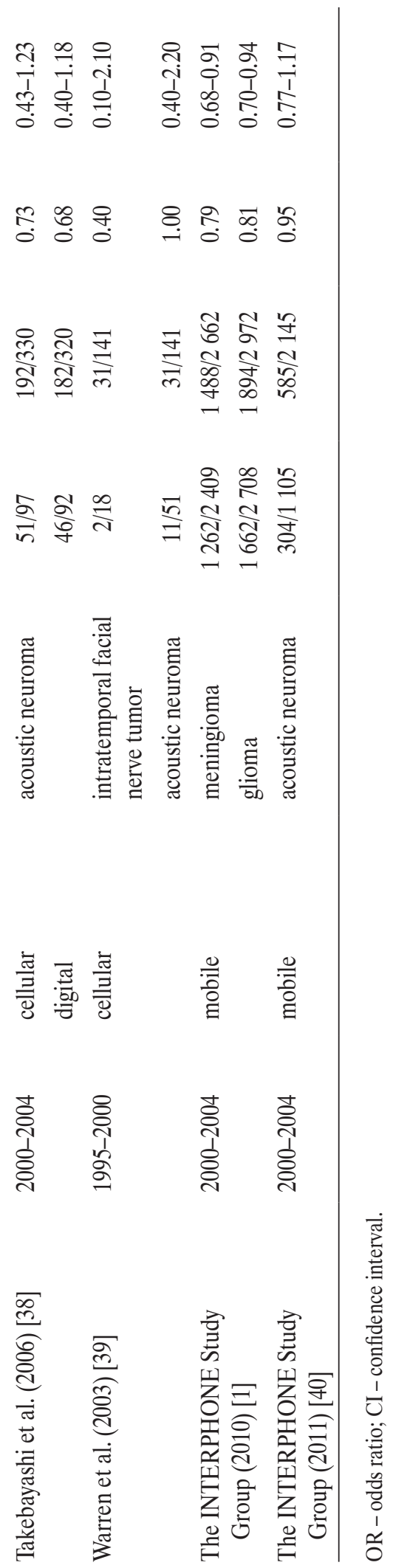

\section{Statistics}

In order to pool the results of the different studies, we should assume that these results would give an evaluation effect which would be the same for all studies, and that the effects evaluated would be a part of the same distribution (sample estimates of the same mean). This assumption should be verified with a statistical test, the test for heterogeneity. If this is correct, in further analysis we can use formulas based on this assumption, known as the fixed effects model. If we are not constrained by the studies belonging to the same population (i.e., the studies evaluated are sampled from a population that contains several sub-populations, each with its own mean), and therefore we assume that the variability of the results depends on the variability of the intra- and inter-studies, we will use procedures called the random effects models [27].

The studies included in the meta-analysis may differ both in the design and applied methods. They may also vary in the participants, exposure and resultant variable. Such diversity is usually considered to be a methodological or clinical heterogeneity of studies. The statistical heterogeneity occurs when true effects in the individual studies are assessed in different ways [28].

The most popular test used to detect heterogeneity of studies is the Q-Cochran test and it was applied in our meta-analysis.

In considering the method of risk calculation, the first stage of our meta-analysis comprised assessing the homogeneity of the studies included in the meta-analysis. A standard $\mathrm{Chi}^{2}$ test was employed $[28,29]$ to verify the question of testing:

$$
\left\{\begin{array}{l}
\mathrm{H}_{0} \text { : homogeneity of studies } \\
\mathrm{H}_{1} \text { : heterogeneity of studies }
\end{array}\right.
$$

Depending on the homogeneity assessment result:

- a fixed effect model with Peto, Gart and Mantel-Haenszel tests was employed for homogeneity of studies ( $\mathrm{p}$ in the Q-Cochran test > 0.05) (all 3 tests resulted in the same conclusion concerning the analyzed data), 
- random effect model was used for heterogeneity of studies ( $\mathrm{p}$ in the Q-Cochran test < 0.05).

In fixed effects models as well as random effects models, odds ratio (OR) and $95 \%$ confidence interval (CI) for the OR were determined. The Leonardo (2005) software was used for the calculations [27].

\section{RESULTS}

\section{All intracranial tumors and all mobile phone types}

The studies included in that analysis are shown in the Table 1. The Q-Cochran test indicated heterogeneity of the studies which were used in the meta-analysis ( $p<0.0005)$, and therefore in that case, the random effect model was used. The results obtained in that model show no relationship between mobile phone use and the risk of an intracranial tumor $(\mathrm{OR}=0.94,95 \% \mathrm{CI}: 0.86-1.03)$.

\section{All brain tumors and analogue phones}

The studies included in that analysis are shown in the Table 1. The Q-Cochran test indicated that the studies used in the meta-analysis were not homogenous ( $p<0.0005)$, and therefore in that case, the random effect model was used. The results obtained in that model show no relationship between mobile phone use and the risk of brain cancer $(\mathrm{OR}=1.09,95 \%$ CI: 0.91-1.3).

\section{Glioma and all mobile phone types}

The studies included in that analysis are shown in the Table 1. The Q-Cochran test indicated that the studies used in the meta-analysis were not homogenous ( $\mathrm{p}<0.015$ ), and so in that case, the random effect model was used. The results obtained in that model show no relationship between mobile phone use and the risk of glioma $(\mathrm{OR}=0.92,95 \%$ CI: 0.83-1.03).

\section{Meningioma and all mobile phone types}

The studies included in that analysis are shown in the Table 1.
The Q-Cochran test indicated that the studies used in the meta-analysis were not homogenous $(\mathrm{p}<0.05)$, and so in that case, the random effect model was used. The results obtained in that model show no relationship between mobile phone use and the risk of meningioma (OR $=0.72,95 \%$ CI: 0.6-0.86).

\section{Acoustic neuroma and all mobile phone types}

The studies included in that analysis are shown in the Table 1. The Q-Cochran test indicated that it would not be reasonable to reject the hypothesis that the studies in the meta-analysis were homogenous $(p=0.710)$. Therefore, the fixed effects model was used. In the individual models (Peto test, Gart test and Mantel-Haenszel test), the same results were obtained (OR $=0.96,95 \%$ CI: 0.87-1.06). In all 3 tests, OR was lower than 1, which indicated that there was no relationship between mobile phone use and the risk of acoustic neuroma.

\section{All intracranial tumors and all phone types (time of mobile phone use: $\geq 10$ years)}

The studies included in that analysis are shown in the Table 2. The analysis of homogeneity revealed that the analyzed studies were not homogenous ( $p<0.0005)$. Thus, the random effects model was used. The results obtained in the random effects model indicated that there was a significant relationship between mobile phone use for longer than 10 years and the risk of intracranial tumors $(\mathrm{OR}=1.46,95 \%$ CI: 1.07-1.98).

\section{Total intracranial tumors and all phone types (time from the first regular use of mobile phone: $\geq 10$ years)}

The studies included in that analysis are shown in the Table 3. The probability in the Q-Cochran test is less than 0.0005 , which means that the studies in the analysis are nonhomogenous. Because OR is significantly greater than 1 $(\mathrm{OR}=1.25,95 \%$ CI: 1.04-1.52), we can conclude that 


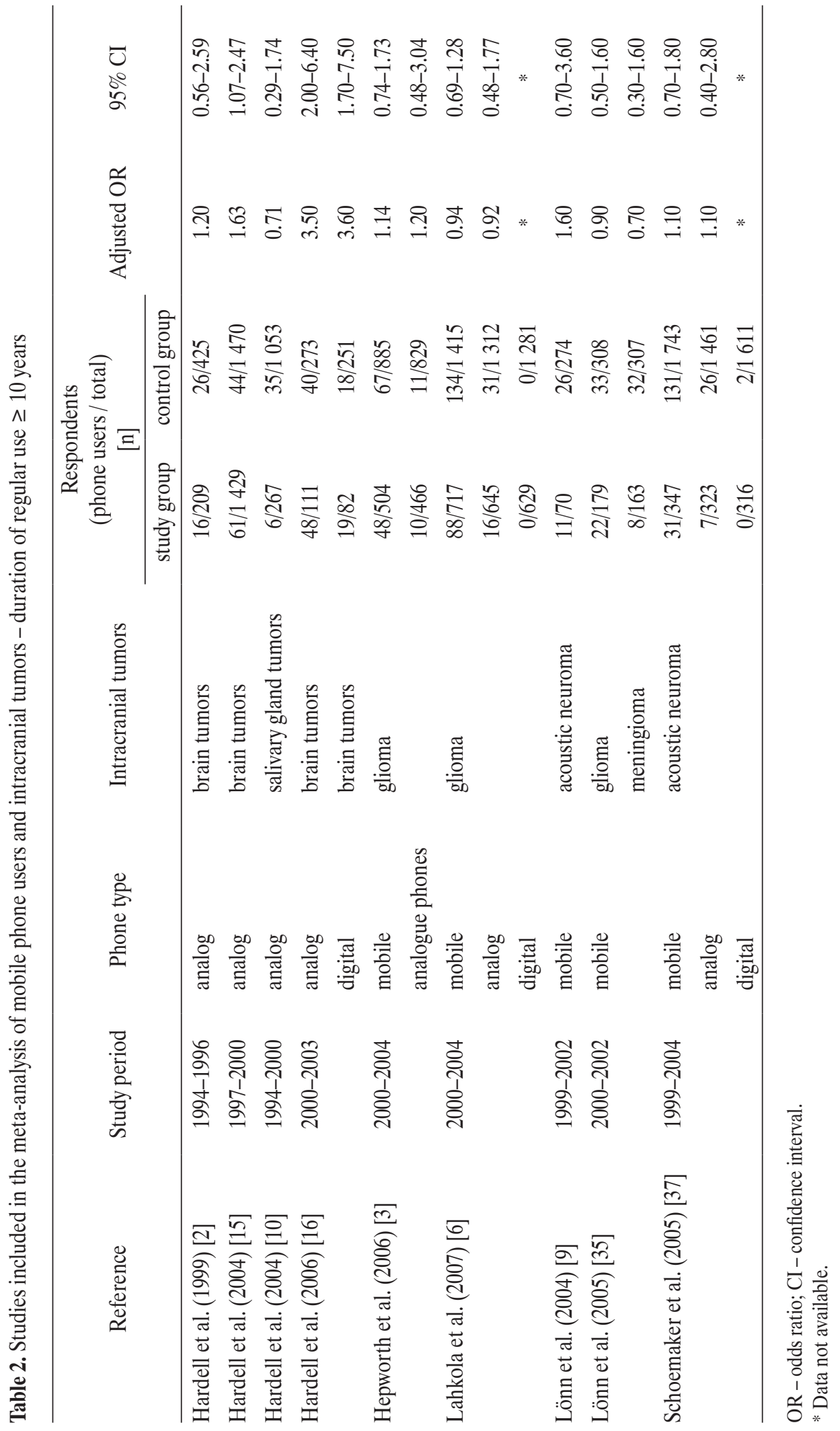




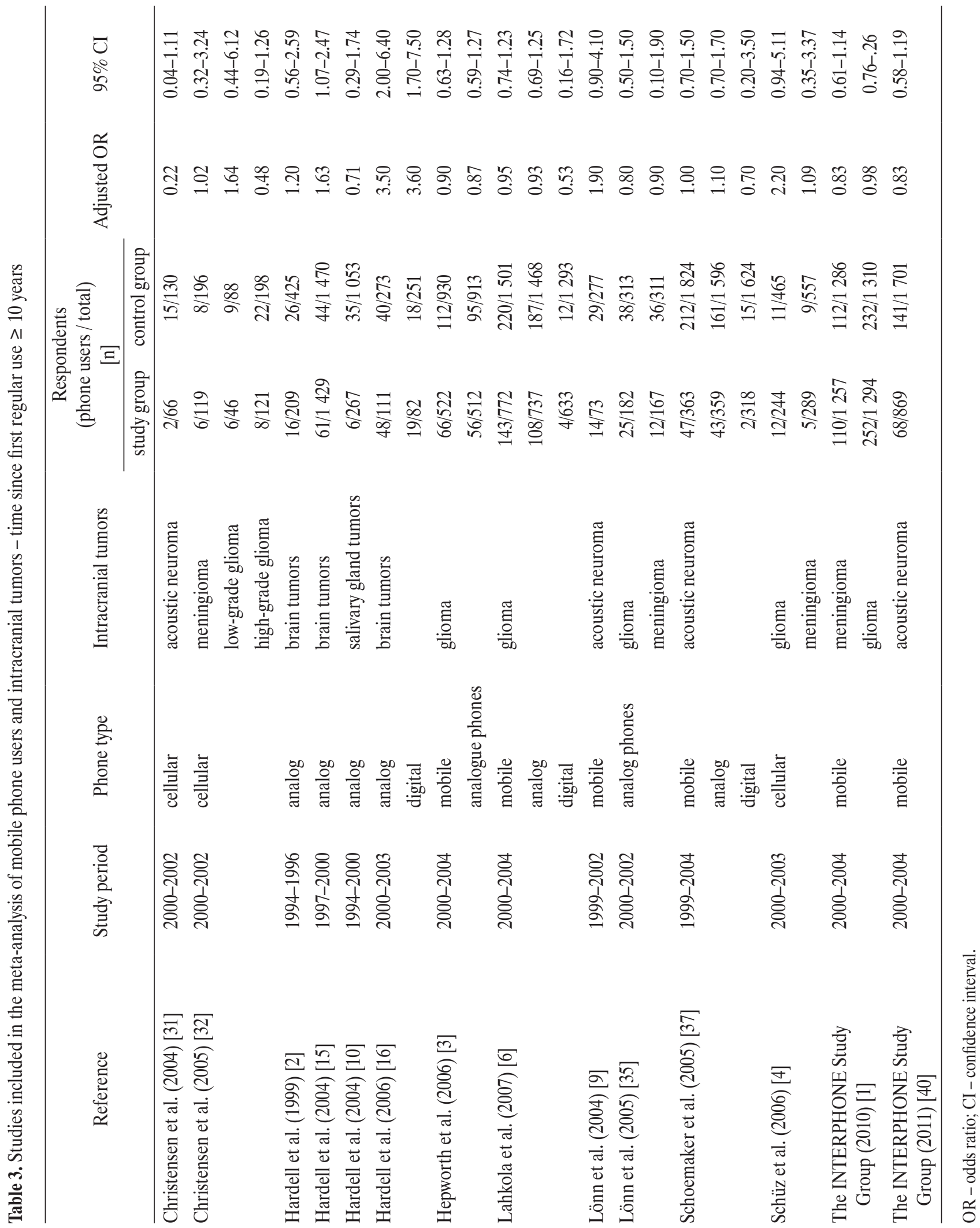


there is a significant relationship between the time from the first regular use of mobile phone of 10 years or more and the risk of intracranial tumors.

\section{All intracranial tumors and all phone types (ipsilateral exposure)}

The studies included in that analysis are shown in the Table 4. The result of the Q-Cochran test indicates that the studies included in the meta-analysis are non-homogenous $(\mathrm{p}<0.0005)$ and the random effects model should be used to assess OR. Since OR is greater than 1 $(\mathrm{OR}=1.29,95 \% \mathrm{CI}: 1.06-1.57)$, there is a significant relationship between ipsilateral use of mobile phone and the risk of intracranial tumor.

\section{DISCUSSION}

We found a significant relationship between:

- all intracranial tumors and all phone types; ipsilateral exposure;

- all intracranial tumors and all phone types, when the time of mobile phone use was not shorter than 10 years;

- all intracranial tumors and all phone types when the time from the first regular use of mobile phone was 10 years or more.

In 2006, Lahkola et al. [18] performed a meta-analysis of the results of 12 epidemiological studies completed in 2005 on the relationship between various intracranial tumors and the use of mobile phones. It included 2780 cases of cancer patients, out of whom 748 had been mobile phone users for 2-5 years. The authors did not detect an increased risk attributable to mobile phone use either for the total of intracranial tumors analyzed together $(\mathrm{OR}=0.98,95 \% \mathrm{CI}: 0.83-$ $1.16)$, or for glioma $(\mathrm{OR}=0.96$, CI $0.78-1.18)$, or meningioma $(\mathrm{OR}=0.87,95 \% \mathrm{CI}: 0.72-1.05)$. Also the risk of acoustic neuroma was similar both for patients using mobile phones on a regular and occasional basis $(\mathrm{OR}=1.07,95 \% \quad \mathrm{CI}: \quad 0.89-1.3$ and $\mathrm{OR}=1.07,95 \% \mathrm{CI}: 0.89-1.3$, respectively).

It is worth nothing that the meta-analysis considered the studies of subjects using mobile phones for 2-5 years. This period is too short to produce any evident symptoms of cancer. Therefore, the negative effect of the study (i.e., no relationship between mobile phone use and tumor development) does not indicate that mobile phones have no effect on the incidence of cancer.

Hardell et al. (2007) [41] analyzed the results of 14 epidemiological studies on people using mobile phones for over 10 years. The authors of 3 studies indicated a 3-4fold increase in the risk of acoustic neuroma, 5 studies reported the highest risk for glioma in the ipsilateral location (tumor located at the side where the phone is usually held) (OR $=5.4,95 \% \mathrm{CI}$ : 3-5.6). People using mobile phones for longer than 10 years were found to be at the highest risk. The authors analyzed also the relationship between tumor and the lifetime dose (total hours of mobile phone use). They found that the risk of cancer associated with the lifetime dose of over $2000 \mathrm{~h}$ in analogue phone users was almost 6 times higher $(\mathrm{OR}=5.9$, 95\% CI: 2.4-14), and in digital phone users almost 4 times higher $(\mathrm{OR}=3.7,95 \% \mathrm{CI}: 1.7-7.7)$ compared to people whose lifetime dose was within $1000 \mathrm{~h}$.

In 2008, Hardell et al. [23] published the results of their meta-analysis covering all studies performed heretofore on the relationship between the incidence of intracranial tumors and mobile phone use. In their meta-analysis, the authors incorporated 19 studies. They demonstrated that in people using mobile phone for over 10 years on a regular basis, the risk of ipsilateral glioma and acoustic neuroma was significantly higher than in people using mobile phone occasionally ( $\mathrm{OR}=2,95 \% \mathrm{CI}$ : $1.2-3.4$ and OR $=2.4,95 \%$ CI: $1.1-5.3$, respectively).

In 2008, Kan et al. [24] published the results of a meta-analysis comprising 9 case-control studies on people using mobile phones for 10 years and longer. 


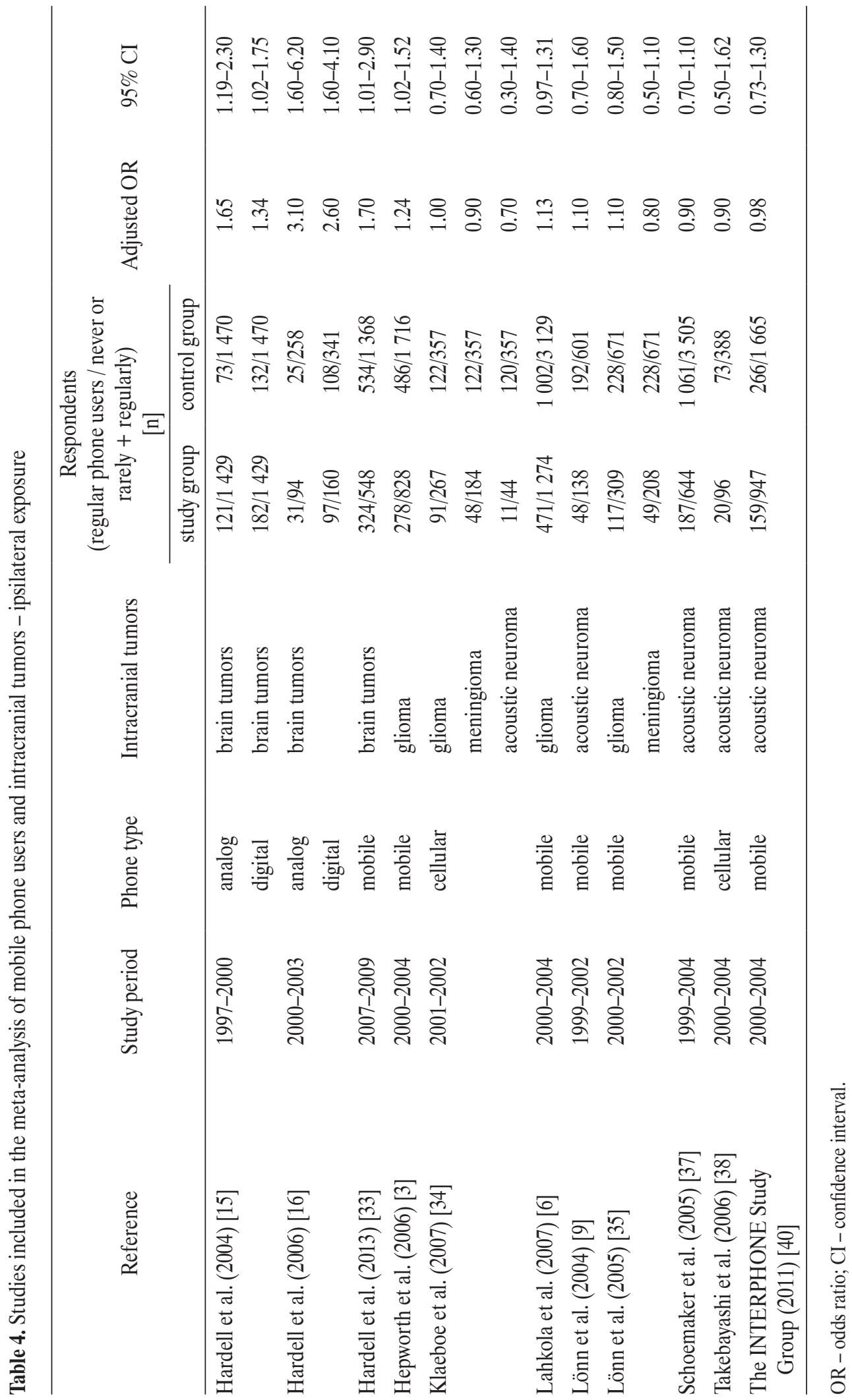


The cases of intracranial tumors (glioma, meningioma, acoustic neuroma) were analyzed in mobile phone users. A significantly higher frequency of brain tumors, OR $=1.25$, 95\% CI: $1.01-1.54$ was detected in people using mobile phones for longer than 10 years, compared to control cases. The analysis performed with the reference to individual tumor types did not show an increased frequency of any single tumor type.

In 2009, Myung et al. [26] published the results of a meta-analysis comprising 23 case-control studies. The results of 8 high-quality blind studies confirmed the detrimental effect of mobile phones on their users compared to non-users or occasional users. The risk of tumor in people using mobile phones for 10 years or longer was $\mathrm{OR}=1.18,95 \% \mathrm{CI}: 1.04-1.34$. The analysis comprised 13 studies. It was performed without regard to tumor types.

Khurana et al. (2009) in their review covering all studies analyzing the risk of intracranial tumors in long-term users of mobile phones ( $\geq 10$ years) showed a significantly higher risk for glioma and acoustic neuroma. No such relationship was noted for meningioma [25].

It is difficult to compare the results of our meta-analysis with earlier studies, because the methodology of analysis was different.

Lahkola et al. (2006) [18] did not analyze the risk for people using mobile phones for longer than 10 years. We included into our meta-analysis studies specifying both the time of the regular mobile phone use over 10 years, and the time following the first regular use of 10 years or longer.

Hardell et al. (2008) [23] did not analyze the risk for all tumors together, they analyzed the risk for glioma, meningioma, and acoustic neuroma separately. We did not analyze the risk separately for each type of tumor in people using mobile phones longer than 10 years, because in our opinion the number of studies was too small to make such an analysis feasible.
A meta-analysis by Myung et al. (2009) [26] was performed without the reference either to individual tumor types or ipsi- or contralateral use of mobile phones.

It should be noted, however, that the results of the studies of Kan et al. (2008) [24] and Myung et al. (2009) [26], similarly to our meta-analysis, show a significant relationship between the location of tumor (regardless of tumor type) and the use of mobile phones for over 10 years.

No relationship between the risk of meningioma and mobile phone use is in line with all meta-analyses performed heretofore.

The comparison between our studies and other meta-analyses is displayed in the Table 5.

We are not able to compare our results with reference to different kinds of intracranial tumors (glioma, meningioma, acoustic neuroma) in relation to time of using mobile phones. A reliable analysis was not feasible because, in our opinion, the number of original works is too small. Due to the same reasons, a comparison between our meta-analysis and other studies in relation to the effects side of using mobile phones (ipsilateral use) is possible also only for the total number of tumors. In Lakhola et al. (2006) [18], the risk of all intracranial tumors was 1.36 (95\% CI: 0.991.87), in Hardell et al. (2013) [33] it was 1.7 (95\% CI: 1.01$2.9)$ vs. results of our own study presented in this article 1.25 (95\% CI: 1.02-1.53).

Generally, our results are in accordance with the results published by Hardell et al. (2011) [42] in their pooled analysis, who found an increased risk of malignant brain tumors in people using mobile phones for longer than 10 years and in the latest review published by Morgan et al. [43] in 2015. This review comprises results of the latest case control French national study (CERENAT) published by Coureau et al. (2014) [44]. They found a positive, statistically significant association between some intracranial tumors and the number of calls as well as with the life-long cumulative duration of calls. Our meta-analysis related to intracranial tumors in 


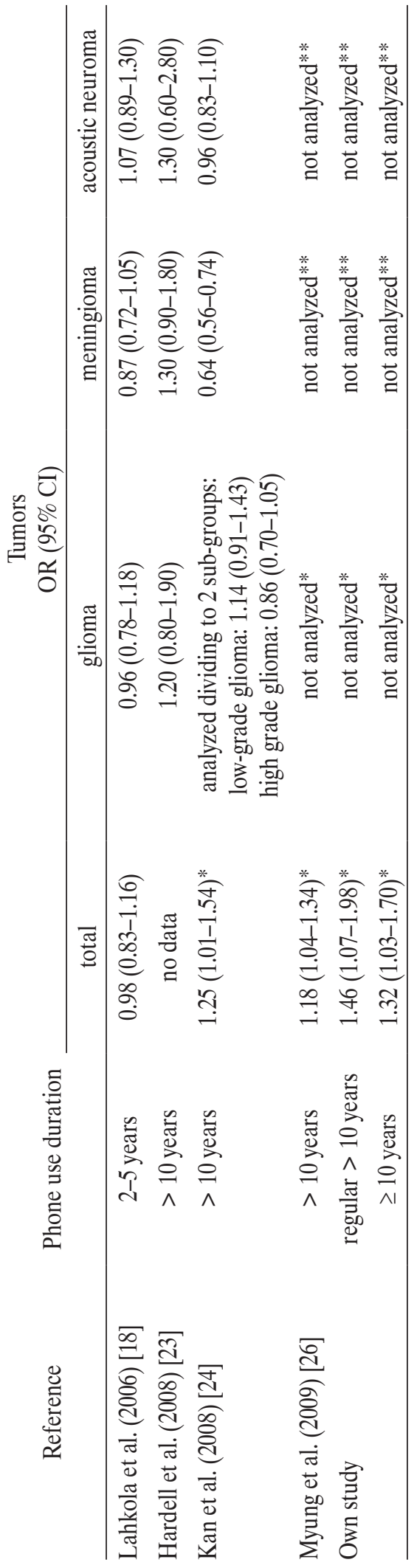

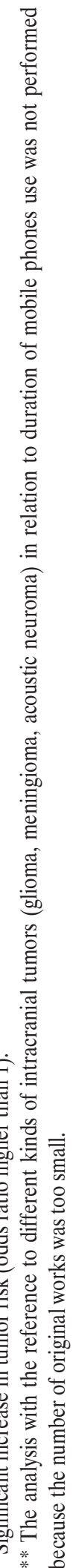

long-term users is in concordance also with the results of CERENAT study.

The limitations of our study result from the limitations of the individual case-control studies, particularly those related to exposure assessment and long latency of the intracranial tumors. On the other hand, using meta-analysis enables to avoid the problem of small groups, and allows to draw reliable conclusions in spite of contradicting results of the individual case-control studies.

\section{CONCLUSIONS}

Our results support the hypothesis that long-term (over 10 years) use of mobile phones increases the risk of intracranial tumors, especially in the case of ipsilateral exposure. The same conclusions are valid for the work by Davis et al. (2013) [45], who reviewed papers on the association between the use of wireless (mobile and cordless) phones and intracranial tumors. Those authors stress that the risk of tumors in people who have used the phone for periods longer than 10 years is significantly elevated. In people who had started using the phone on a regular basis before they were 20 years old, the risk of ipsilateral glioma was found to be fourfold higher. Hardell et al. (2013) [46] stress the significance of the "lifetime exposure dose." For an exposure of $\geq 1640 \mathrm{~h}$, the risk of ipsilateral acoustic neuroma is 2.55 (95\% CI: $1.5-4.4$ ).

These results are in concordance with the conclusion of the expert panel for the International Agency for Research on Cancer (IARC), that cell phones are possibly carcinogenic (Group 2B) [47]. More research is needed to confirm that electromagnetic fields emitted by mobile phones are carcinogenic to humans.

\section{REFERENCES}

1. The INTERPHONE Study Group. Brain tumour risk in relation to mobile telephone use: Results of the INTERPHONE international case-control study. Int J Epidemiol. 2010;39(3):675-94, https://doi.org/10.1093/ije/dyq079. 
2. Hardell L, Näsman A, Påhlson A, Hallquist A, Hansson Mild K. Use of cellular telephones and the risk for brain tumours: A case-control study. Int J Oncol. 1999;15(1):113-6, https://doi.org/10.3892/ijo.15.1.113.

3. Hepworth SJ, Schoemaker MJ, Muir KR, Swerdlow AJ, van Tongeren MJ, McKinney PA. Mobile phone use and risk of glioma in adults: Case-control study. BMJ. 2006;32(7546): 883-7, https://doi.org/10.1136/bmj.38720.687975.55.

4. Schüz J, Jacobsen R, Olsen JH, Boice JD Jr, McLaughlin JK, Johansen C. Cellular telephone use and cancer risk: Update of a nationwide Danish cohort. J Natl Cancer Ins. 2006;98(23):1707-13, https://doi.org/10.1093/jnci/ djj464.

5. Auvinen A, Hietanen M, Luukkonen R, Koskela RS. Brain tumours and salivary gland cancers among cellular telephone users. Epidemiology. 2002;13(3):356-9, https://doi. org/10.1097/00001648-200205000-00018.

6. Lahkola A, Auvinen A, Raitanen J, Schoemaker MJ, Christensen HC, Feychting M, et al. Mobile phone use and risk of glioma in 5 North European countries. Int J Cancer. 2007;120(8):1769-75, https://doi.org/10.1002/ijc.22503.

7. Inskip PD, Tarone RE, Hatch EE, Wilcosky TC, Shapiro WR, Selker RG, et al. Cellular-telephone use and brain tumors. N Engl J Med. 2013;44(2):79-86, https://doi. org/10.1056/NEJM200101113440201.

8. Lahkola A, Salminen T, Raitanen J, Heinävaara S, Schoemaker MJ, Christensen HC, et al. Meningioma and mobile phone use - A collaborative case-control study in 5 North European countries. Int J Epidemiol. 2008;37(6):1304-13, https://doi.org/10.1093/ije/dyn155.

9. Lönn S, Ahlbom A, Hall P, Feychting M. Mobile phone use and the risk of acoustic neuroma. Epidemiology. 2004;15(6): 653-9, https://doi.org/10.1097/01.ede.0000142519.00772.bf.

10. Hardell L, Hallquist A, Hansson Mild K, Carlberg M, Gertzén H, Schildt EB, et al. No association between the use of cellular or cordless telephones and salivary gland tumours. Occup Environ Med. 2004;61(8):675-9, https://doi. org/10.1136/oem.2003.011262.
11. Lönn S, Ahlbom A, Christensen HC, Johansen C, Schüz J, Edström S, et al. Mobile phone use and risk of parotid gland tumor. Am J Epidemiol. 2006;164(7):637-43, https://doi.org/ 10.1093/aje/kwj242.

12. Sadetzki S, Chetrit A, Jarus-Hakak A, Cardis E, Deutch Y, Duvdevani $S$, et al. Cellular phone use and risk of benign and malignant parotid gland tumors - A nationwide case-control study. Am J Epidemiol. 2008;167(4):457-67, https://doi.org/ 10.1093/aje/kwm325.

13. Stang A, Anastassiou G, Ahrens W, Bromen K, Bornfeld N, Jöckel $\mathrm{KH}$. The possible role of radiofrequency radiation in the development of uveal melanoma. Epidemiology. 2001;12(1):1-4, https://doi.org/10.1097/00001648-20010 1000-00003.

14. Takebayashi T, Varsier N, Kikuchi Y, Wake K, Taki M, Watanabe $S$, et al. Mobile phone use, exposure to radiofrequency electromagnetic field, and brain tumor: A case-control study. Br J Cancer. 2008;98(3):652-9, https://doi.org/10.1038/sj.bjc. 6604214.

15. Hardell L, Hansson Mild K, Carlberg M, Hallquist A. Cellular and cordless telephone use and the association with brain tumors in different age groups. Arch Environ Health. 2004;59(3):132-7, https://doi.org/10.3200/AEOH. 59.3.132-137.

16. Hardell L, Carlberg M, Hansson Mild K. Case-control study of the association between the use of cellular and cordless telephones and malignant brain tumors diagnosed during 2000-2003. Environ Res. 2006;100(2):232-41, https://doi.org/ 10.1016/j.envres.2005.04.006.

17. Hansson Mild K, Carlberg M, Wilén J, Hardell L. How to combine the use of different mobile and cordless telephones in epidemiological studies on brain tumours? Eur J Cancer Prev. 2005;14(3):285-8, https://doi.org/10.1097/ 00008469-200506000-00015.

18. Lahkola A, Tokola K, Auvinen A. Meta-analysis of mobile phone use and intracranial tumors. Scand J Work Environ Health. 2006;32(3):171-7, https://doi.org/10.5271/ sjweh.995. 
19. Croft RJ, McKenzie RJ, Inyang I, Benke GP, Anderson V, Abramson MJ. Mobile phones and brain tumours: A review of epidemiological research. Australas Phys Eng Sci Med. 2008;31(4):255-7, https://doi.org/10.1007/BF03178595.

20. Levis AG, Minicuci N, Ricci P, Gennaro V, Garbisa S. Mobile phones and head tumours. The discrepancies in causeeffect relationships in the epidemiological studies - How do they arise? Environ Health. 2011;10:59, https://doi.org/ 10.1186/1476-069X-10-59.

21. Repacholi MH, Lerchl A, Röösli M, Sienkiewicz Z, Auvinen A, Breckenkamp J, et al. Systematic review of wireless phone use and brain cancer and other head tumors. Bioelectromagnetics. 2012;33(3):187-206, https://doi.org/10.1002/bem.20716.

22. Szmigielski S. Cancer risks related to low-level RF/MW exposures, including cell phones. Electromagn Biol Med. 2013;32(3):273-80, https://doi.org/10.3109/15368378.2012. 701192.

23. Hardell L, Carlberg M, Söderqvist F, Hansson Mild K. Meta-analysis of long-term mobile phone use and the association with brain tumours. Int J Oncol. 2008;32(5):1097-103, https://doi.org/10.3892/ijo.32.5.1097.

24. Kan P, Simonsen SE, Lyon JL, Kestle JR. Cellular phone use and brain tumor: A meta-analysis. J Neurooncol. 2008;86(1):71-8, https://doi.org/10.1007/s11060-007-9432-1.

25. Khurana VG, Teo C, Kundi M. Cell phones and brain tumors: A review including the long-term epidemiologic data. Surg Neurol. 2009;72(3):205-14, https://doi.org/10.1016/ j.surneu.2009.01.019.

26. Myung SK, Ju W, McDonnell DD, Lee YJ, Kazinets G, Cheng CT, et al. Mobile phone use and risk of tumors: A meta-analysis. J Clin Oncol. 2009;27(33):5565-72, https:// doi.org/10.1200/JCO.2008.21.6366.

27. Leandro G. Meta-analysis in medical research: The handbook for the understanding and practice of meta-analysis. Oxford: Blackwell Publishing Ltd; 2005.

28. Higgins JPT, Thompson SG Quantifying heterogeneity in a meta-analysis. Stat Med. 2002;21(11):1539-58, https://doi. org/10.1002/sim.1186.
29. Baujat B, Mahe C, Pignon J-P, Hill C. A graphical method for exploring heterogeneity in meta-analyses: Application to a meta-analysis of 65 trials. Stat Med. 2002;21(18):2641-52, https://doi.org/10.1002/sim.1221.

30. Carlberg M, Söderqvist F, Hansson Mild K, Hardell L. Meningioma patients diagnosed 2007-2009 and the association with use of mobile and cordless phones: A case-control study. Environ Health. 2013;12(1):60, https://doi.org/10.1186/1476069X-12-60.

31. Christensen HC, Schüz J, Kosteljanetz M, Poulsen HS, Thomsen J, Johansen C. Cellular telephone use and risk of acoustic neuroma. Am J Epidemiol. 2004;159(3):277-83, https://doi.org/10.1093/aje/kwh032.

32. Christensen HC, Schüz J, Kosteljanetz M, Poulsen HS, Boice JD Jr, McLaughlin JK, et al. Cellular telephones and risk for brain tumors: A population-based, incident casecontrol study. Neurology. 2005;64(7):1189-95, https://doi. org/10.1212/01.WNL.0000156351.72313.D3. Erratum in: Neurology. 2005;65:1324, https://doi.org/10.1212/WNL.65. 8.1324.

33. Hardell L, Carlberg M, Söderqvist F, Hansson Mild K. Casecontrol study of the association between malignant brain tumours between 2007 and 2009 and mobile and cordless phone use. Int J Oncol. 2013;43(6):1833-45, https://doi.org/ 10.3892/ijo.2013.2111.

34. Klaeboe L, Blaasaas KG, Tynes T. Use of mobile phones in Norway and risk of intracranial tumours. Eur J Cancer Prev. 2007;16(2):158-64, https://doi.org/10.1097/01.cej.000020361 6.77183.4c.

35. Lönn S, Ahlbom A, Hall P, Feychting M; Swedish Interphone Study Group. Long-term mobile phone use and brain tumor risk. Am J Epidemiol. 2005;161(6):526-35, https://doi. org/10.1093/aje/kwi091.

36. Muscat JE, Malkin MG, Thompson S, Shore RE, Stellman SD, McRee D, et al. Handheld cellular telephone use and risk of brain cancer. JAMA. 2000;284(23):3001-7, https:// doi.org/10.1001/jama.284.23.3001. Erratum in: JAMA. 2001; 286:1293. 
37. Schoemaker MJ, Swerdlow AJ, Ahlbom A, Auvinen A, Blaasaas KG, Cardis E, et al. Mobile phone use and risk of acoustic neuroma: Results of the Interphone case-control study in 5 North European countries. Br J Cancer. 2005;93(7):842-8, https://doi.org/10.1038/sj.bjc.6602764.

38. Takebayashi T, Akiba S, Kikuchi Y, Taki M, Wake K, Watanabe $\mathrm{S}$, et al. Mobile phone use and acoustic neuroma risk in Japan. Occup Environ Med. 2006;63(12):802-7, https://oi. org/10.1136/oem.2006.028308.

39. Warren HG, Prevatt AA, Daly KA, Antonelli PJ. Cellular telephone use and risk of intratemporal facial nerve tumor. Laryngoscope. 2003;113(4):663-7, https://doi.org/10.1097/00 005537-200304000-00015.

40. The INTERPHONE Study Group. Acoustic neuroma risk in relation to mobile telephone use: Results of the INTERPHONE international case-control study. Cancer Epidemiol. 2011;35(5):453-64, https://doi.org/10.1016/j.canep.2011. 05.012 .

41. Hardell L, Carlberg M, Söderqvist F, Hansson Mild K, Morgan LL. Long-term use of cellular phones and brain tumours: Increased risk associated with use for $\geq 10$ years. Occup Environ Med. 2007;64(9):626-32, https://doi.org/10.1136/ oem.2006.029751.

42. Hardell L, Carlberg M, Hansson Mild K. Pooled analysis of case-control studies on malignant brain tumours and the use of mobile and cordless phones including living and deceased subjects. Int J Oncol. 2011;38(5):1465-74, https:// doi.org/10.3892/ijo.2011.947.

43. Morgan LL, Miller AB, Sasco A, Davis DL. Mobile phone radiation causes brain tumors and should be classified as a probable human carcinogen (2A) (review). Int J Oncol. 2015;46(5):1865-71, https://doi.org/10.3892/ijo.2015.2908.

44. Coureau G, Bouvier G, Lebailly P, Fabbro-Peray P, Gruber A, Leffondre K, et al. Mobile phone use and brain tumours in the CERENAT, case-control study. Occup Environ Med. 2014;71(7):514-22, https://doi.org/10.1136/oemed-20 13-101754.

45. Davis DL, Kesari S, Soskolne CL, Miller AB, Stein Y. Swedish review strengthens grounds for concluding that radiation from cellular and cordless phones is a probable human carcinogen. Pathophysiology. 2013;20(2):123-9, https://doi. org/10.1016/j.pathophys.2013.03.001.

46. Hardell L, Carlberg M, Hansson Mild K. Use of mobile phones and cordless phones is associated with increased risk for glioma and acoustic neuroma. Pathophysiology. 2013;20(2):85-110, https://doi.org/10.1016/j.pathophys.2012. 11.001.

47. Grigor'ev IuG. [The probability of developing brain tumours among users of cellular telephones (scientific information to the decision of the International Agency for Research on Cancer (IARC) announced on May 31, 2011)]. Radiats Biol Radioecol. 2011;51(5):633-8. Russian.

This work is available in Open Access model and licensed under a Creative Commons Attribution-NonCommercial 3.0 Poland License - http://creativecommons.org/ licenses/by-nc/3.0/pl/deed.en. 